\title{
Meninas de Moral: Experiências Socioeducativas em um Bairro Popular do Recife
}

Girls Of Morality: Socioeducational Experiences in a Popular District of Recife

Niñas de Moral: Experiencias Socioeducativas en un Barrio Popular de Recife

Rosineide de Lourdes Meira Cordeiro, Evandro Alves Barbosa Filho, Giselle Maria Nanes Correia dos Santos, Luanne Alves Oliveira \& Raíssa Barbosa Araújo
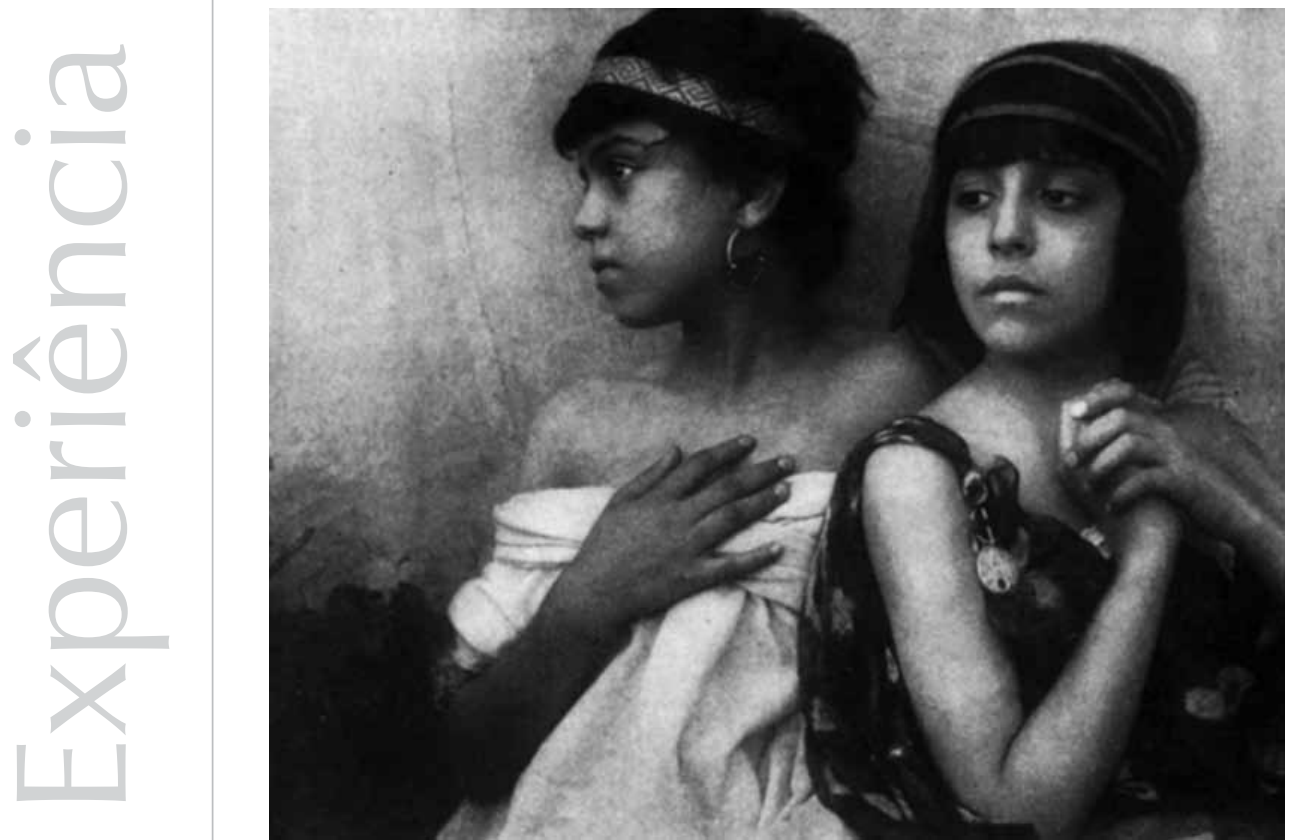
Resumo: Este artigo apresenta uma experiência de extensão universitária que objetivou promover um espaço socioeducativo com adolescentes do sexo feminino no universo dos direitos sexuais e sociais. $\mathrm{O}$ projeto foi desenvolvido por duas estudantes de Psicologia e dois de Serviço Social, sob orientação docente, com dez garotas de idade entre 12 e 14 anos, majoritariamente afro-descendentes, moradoras da periferia da cidade do Recife, Pernambuco. O artigo enfoca o uso do termo menina de moral pelas adolescentes que, dentre outros significados e implicações, envolve uso de força física, ameaças verbais e drogas lícitas e ilícitas como elementos que conferem ou mantêm status e respeito entre pares. As ações da menina de moral sinalizam uma série de estratégias elaboradas pelas adolescentes ante as singularidades do contexto social em que estão inseridas e revelam que os condicionantes de geração são entremeados por fatores como gênero, classe social, raça e etnia.

Palavras-chave: Garotas. Classes populares. Violência. Drogas.

\begin{abstract}
This article reflects an experience of university extension which aimed to promote a socioeducational space with female adolescents in the context of social and sexual rights. Directed by two students of psychology and two of social work, under the guidance of a teacher, the project was developed with ten girls, between 12 and 14 years, mostly African-Americans, who live in a community in the outskirts of Recife, PE, Brazil. The article focuses the use of the term girl of morality used by these adolescents which, among other meanings and implications, involves the use of physical force, verbal threats and legal and illegal drugs as elements that award or keep status and respect among peers. Actions of the girl of morality signal a series of strategies developed by them in the singularities of the social context in which they are involved and also show that the conditions of generation are permeated by elements as gender, social class, race and ethnicity.
\end{abstract}

Keywords: Girls. Lower classes. Violence. Drugs.

Resumen: Este artículo presenta una experiencia de extensión universitaria que tuvo como objetivo promover un espacio socioeducativo con adolescentes del sexo femenino en el universo de los derechos sexuales y sociales. El proyecto fue desarrollado por dos estudiantes de Psicología y dos de Servicio Social, bajo orientación docente, con diez chicas de edad entre 12 y 14 años, mayoritariamente afro-descendientes, habitantes de la periferia de la ciudad de Recife, Pernambuco. El artículo enfoca el uso del término niña de moral por las adolescentes que, entre otros significados e implicaciones, implica el uso de fuerza física, amenazas verbales y drogas lícitas e ilícitas como elementos que confieren o mantienen estatus y respeto entre pares. Las acciones de la niña de moral señalizan una serie de estrategias elaboradas por las adolescentes ante las singularidades del contexto social en que están inseridas y revelan que los condicionantes de generación son entremediados por factores como género, clase social, raza y etnia.

Palabras clave: Chicas. Clases populares. Violencia. Drogas.

Este artigo tem como base uma experiência desenvolvida em um projeto de extensão universitária que objetivou promover um espaço socioeducativo de reflexão e trabalho com adolescentes do sexo feminino, visando ao seu empoderamento no universo dos direitos sociais e sexuais. Sob supervisão docente, esse trabalho foi desenvolvido no segundo semestre de 2007, por duas graduandas de Psicologia e uma graduanda e um graduando de Serviço Social. Os dois primeiros meses foram dedicados exclusivamente à revisão teórica, à discussão em grupo e ao direcionamento dos objetivos do projeto, e, nos quatro meses seguintes, além dessas atividades, foi também realizado o trabalho em campo.
Realizamos as ações interventivas junto a 10 adolescentes do sexo feminino, de faixa etária entre 12 e 14 anos, majoritariamente afro-descendentes, residentes em uma comunidade de periferia da cidade do Recife, em Pernambuco. A comunidade está localizada no maior bairro da cidade $\left(46 \mathrm{~km}^{2}\right)$ e integra a 3a Região Político-administrativa do Recife (RPA-3). Esse bairro apresenta hibridez urbano-rural, pois parte dele $\left(36,74 \mathrm{~km}^{2}\right)$ está sobre uma zona especial de proteção ambiental (ZEPA), a Guabiraba-Pau Ferro (www.recipe.pe.gov.br). A população do bairro é de aproximadamente 7.318 habitantes, não sendo relevante a diferença populacional entre homens e mulheres (3.691 e 3.627, respectivamente). Quanto 
à faixa etária, observa-se a prevalência de jovens e de adultos jovens. A taxa geométrica de crescimento anual é de 4,46 , e a taxa habitante/domicílio é de 4,04 (www.recipe. pe.gov.br). ${ }^{1}$

$\mathrm{Na}$ comunidade onde se realizou a intervenção, a maioria das ruas não é asfaltada, e a infra-estrutura básica de saneamento não atende toda a comunidade. Existe apenas uma linha de transporte público e somente uma área pública de recreação e lazer, a quadra poliesportiva, que foi construída por uma indústria de cerveja localizada no mesmo bairro.

Há acentuada desigualdade socioeconômica na comunidade. No mesmo território, coexistem uma paisagem de periferia urbana, com morros e escadarias (onde predomina o risco de haver queda de barreiras), e uma paisagem campestre, com granjas, chácaras e condomínios fechados, tudo cercado por mata exuberante. Ambos os espaços são desprovidos de pavimentação.

De acordo com moradores(as), não há creches nem escolas municipais. Existem apenas escolas particulares, que oferecem formação em ensino fundamental de $1 \underline{\underline{a}}$ a $4^{\underline{a}}$ série (uma delas trabalha em convênio com a prefeitura do Recife), e uma escola estadual, que oferece formação em ensino fundamental de $5^{\mathrm{a}}$ a $8^{\mathrm{a}}$ série e ensino médio. No tocante aos serviços de saúde, a comunidade dispõe de uma unidade do Programa de Saúde da Família (PSF), com duas equipes. Segundo relatos das agentes comunitárias de saúde, a comunidade apresenta altos índices de gravidez não planejada na adolescência, o que evidencia potenciais fatores de risco de ocorrer infecções sexualmente transmissíveis (ISTs).

As adolescentes que participaram da experiência foram convidadas por nós, da equipe do projeto de extensão, e por uma agente comunitária de saúde que trabalha no PSF, residente na mesma comunidade das participantes. Realizamos o projeto em parceria com a Associação Casa Verde, que nos concedeu um espaço reservado de suas instalações físicas para o desenvolvimento das atividades.

\section{Dinâmica das atividades}

Por meio de oficinas temáticas semanais, dialogamos com as adolescentes sobre as assimetrias de gênero presentes em diferentes dimensões da vida bem como trocamos saberes no campo da saúde sexual e reprodutiva, a fim de estimular o conhecimento e as práticas de uma vivência cidadã. Os encontros foram registrados em diário de campo, e alguns deles foram gravados em vídeo e transcritos.

As oficinas tiveram três eixos temáticos: gênero, direitos sexuais e reprodutivos e, por último, infecções sexualmente transmissíveis (ISTs) - HIV/AIDS. No eixo sobre gênero, abordamos as relações de poder, as assimetrias e os papéis sociais tradicionalmente atribuídos a homens e mulheres. É importante pontuar que os diálogos sobre as desigualdades de gênero foram enfocados nesse eixo, mas não se encerraram nele.

No eixo dos direitos sexuais e reprodutivos, as atividades focaram o debate sobre os múltiplos meios de obtenção de prazer com o corpo e os cuidados com ele, com o objetivo de compatibilizar prazeres com práticas saudáveis, e ainda discussões sobre o aborto. No terceiro eixo, tematizamos as ISTs, com enfoque em HIV/AIDS.

De forma geral, o trabalho educativo com as adolescentes seguiu os princípios da educação popular, o que possibilitou seu maior engajamento, pois, como sujeito (e não objeto) do processo educativo, a sua participação foi imprescindível na construção dos conhecimentos. Partimos da realidade e das necessidades apresentadas pelas garotas, considerando as diretrizes do projeto, e promovemos reflexão crítica em torno dos valores hegemônicos que naturalizam 
Freyre (1960) já havia chamado a atenção para os vários "Brasis" existentes no Brasil, destacando sua diversidade, demonstrada em nossos vários "perfis". as diferentes desigualdades sociais. De forma interativa e participativa, as oficinas empregaram diferentes dinâmicas, técnicas e instrumentos pedagógicos.

Essas práticas educativas propiciaram construir uma relação de proximidade entre nós e as participantes. Em nosso trabalho, foi central o investimento na construção de uma relação de confiança e abertura, tomandose o respeito à alteridade como princípio. Durante as oficinas, as garotas expuseram suas realidades de jovens assim como suas experiências de gênero, classe e etnia. Dentre os relatos, as falas que conceituaram o significado de menina de moral foram as que mais nos instigaram.

Guiadas(os) por essas vivências, enfocamos neste artigo o conceito menina de moral utilizado pelas adolescentes. Para tanto, primeiramente apresentamos as adolescentes participantes do projeto. Em seguida, debatemos o uso de força física e de ameaças verbais empregado pelas adolescentes, que ultrapassa o binômio violência-delinquência, elemento que é sobretudo evidenciado como inerente ao mundo de adolescentes e jovens do sexo masculino de classes populares. Logo após, focamos os usos sociais de drogas por essas adolescentes, já que se trata de aspecto prioritário que permeia o conceito em questão.

\section{As adolescentes participantes do projeto}

Tanto estudos acadêmicos quanto o senso comum se referem ao pluralismo cultural existente no Brasil - de classe, étnico-racial e religioso, dentre outros - e apontam a extrema desigualdade na distribuição de renda e as diferenças quanto a cuidados e atenção à saúde, moradia, garantia e qualidade da educação, lazer, etc. Tal problemática, embora se agrave cada vez mais, não é nova. Freyre (1960) já havia chamado a atenção para os vários "Brasis" existentes no Brasil, destacando sua diversidade, demonstrada em nossos vários "perfis". Para compreensão mais abrangente da dinâmica das adolescências brasileiras nas comunidades populares, é necessário avaliar esse período do desenvolvimento e investigar os comportamentos, sentimentos e significados presentes nos(as) adolescentes que vivem em situação de pobreza e, por vezes, de exclusão social.

Nenhuma das adolescentes que participaram do projeto afirmou ter filhos, e todas elas estudam na única escola pública da comunidade. A maioria, durante o período de realização do trabalho, estudava na 4 a série do ensino fundamental, dado que revela defasagem em relação aos adolescentes de outras classes, pois, em média, um adolescente de 12 ou 13 anos já cursa a $6^{\underline{a}}$ ou a 7a série. Apenas uma delas, com 13 anos, está na 8 a série, e é nomeada como a mais estudiosa do grupo e apelidada de "rato de escola".

Em relação ao aspecto cor e raça, duas adolescentes se declararam brancas, duas, negras, e as outras, morenas. A questão da cor de pele não foi alvo de grandes diálogos dentro do grupo, contudo, na primeira oficina, em uma dinâmica de apresentação, uma das adolescentes, que se considerava negra, ao comentar a figura de uma mulher negra, de cabelos crespos e acima do peso padrão, disse: "Ela não se parece comigo... não é por causa da cor dela, eu não tenho preconceito".

Quanto à opção religiosa, o grupo era misto, variava entre catolicismo e religiões evangélicas, e algumas adolescentes declararam não seguir uma religião institucionalizada, apesar de possuir algum sentimento de religiosidade. Nenhuma delas se declarou espírita ou praticante de uma religião afro-brasileira, no entanto, em alguns diálogos, ficou marcante a dupla pertença religiosa. Mesmo quem declarou não seguir uma religião também frequentava cultos nas igrejas evangélicas ou 
as festas de Cosme e Damião nos terreiros das religiões afro-brasileiras.

A respeito das configurações familiares, três das dez adolescentes viviam com os respectivos pais e mães, e as outras garotas moravam apenas com a mãe e cerca de dois irmãos(ãs), em uma média de quatro pessoas por casa. Quatro garotas relataram que moravam em casa própria, e uma relatou que morava em casa "cedida". Quando lhes pedimos que identificassem quem é o(a) chefe do lar, praticamente todas falaram que eram as mães. Algumas delas também relataram que moravam com a mãe na casa da avó e dividiam a mesma casa com primos e tias.

No que se refere à renda familiar, além dos recursos gerados por outros membros da família com trabalhos remunerados formais ou informais, oito garotas afirmaram receber o auxílio Bolsa Família (programa de transferência de renda do governo federal). No entanto, nenhuma das garotas se reconheceu como coprovedora da renda familiar, embora esse auxílio esteja condicionado à frequência escolar das adolescentes.

O modo de vida dessas garotas é contornado por uma perspectiva do imediatismo. Durante as oficinas, praticamente não houve relato de desejo de mudança no futuro ou mesmo questões que versassem sobre um possível momento subsequente à adolescência. Apenas quando eram questionadas diretamente acerca do futuro as adolescentes se posicionavam. Mesmo quando essas questões eram levantadas, as falas não evidenciavam perspectiva de mudança, quer econômica, quer social, em relação ao modo de vida no momento.

Em uma oficina na qual foi utilizada uma técnica do desenho livre que tematizava as configurações familiares do presente e do futuro, apenas uma das adolescentes desenhou figuras e objetos que diferiam de suas condições financeiras atuais. Ela se desenhou ao lado de seu futuro marido e de seus dois filhos, e todos estavam localizados em frente a uma casa de praia e a um carro. Esse desenho foi elaborado pela única adolescente considerada estudiosa pelo grupo.

Em outros momentos, quando questionadas sobre que tipo de profissão gostariam de exercer quando fossem mais velhas, elas citaram: secretária de clínica particular, telefonista, dona de casa e empregada doméstica. Essas expectativas, de certa forma, não fogem ao padrão da divisão sexual de trabalho, que condiciona a inserção das mulheres no mercado de trabalho em determinadas ocupações consideradas femininas.

Hirata (2002) afirma que um dos fatores que vem chamando a atenção dos especialistas quanto à divisão sexual do trabalho, na contemporaneidade, é a bipolarização da inserção profissional feminina. Em um polo, estão profissionais em cargos de chefia e execução e profissionais de nível superior de escolaridade (engenheiras, arquitetas, médicas, professoras universitárias, etc.), e, no outro, encontram-se trabalhadoras com baixa escolaridade em empregos precários, de tempos parciais e temporários (trabalho doméstico remunerado, secretária, caixa de loja ou de supermercado, telefonista etc.).

As poucas mudanças vislumbradas por essas garotas que vivem em situação de vulnerabilidade social podem ser mais bem compreendidas se tomarmos como referência De Leone (1979). Para esse autor, as dificuldades diárias (de estruturação familiar, de acesso a serviços de saúde, educação, políticas de segurança social, etc.) não são o que é mais destrutivo para uma criança e adolescente em situação de pobreza, mas sim, "o fato de que para a maioria delas a vida 
adulta não será significativamente melhor. Para a maioria, o futuro é insignificante" (p.13).

Diante dessas considerações, pode-se pontuar que a trajetória de vida dessas adolescentes é permeada por teias bastante complexas. Os condicionantes de geração são entremeados por outros condicionantes, tais como gênero, classe social, raça e etnia. Trata-se de uma adolescência atropelada por responsabilidades com a casa e irmãos(as), inserção irregular na escola e forte exclusão social.

É usual as garotas relatarem experiências de cuidados cotidianos com a casa e com irmãos(as), primos(as) e filhos(as) de vizinhos(as). Percebemos também desestímulo em relação aos estudos. Segundo os discursos das garotas, a escola não cumpre a função a que se propõe: o corpo docente é resumido e descompromissado, a estrutura física da escola é precária, a segurança é insuficiente, há depredação do ambiente escolar e uso de drogas na escola. Esses fatores são justificados como elementos que não estimulam nem favorecem a frequência escolar.

\section{Meninas de moral}

Ser uma menina de moral significa ser respeitada e admirada pelos garotos e pelas garotas. Esse respeito não é delegado por outrem, ele é conquistado pela própria garota que se propõe a ter "moral". Ela deve se impor diante dos garotos e das outras garotas da comunidade, seja pela coragem de resolver seus próprios problemas, via uso de força física ou ameaça verbal, seja recorrendo ao uso de drogas, que é evidenciado como elemento mediador das relações sociais e é atravessado por significados de prestígio e respeito na convivência entre pares. $\mathrm{Na}$ resolução de problemas, em muitos casos, os conflitos são mediados e dissolvidos via uso de força física ou ameaças verbais. Uma menina de moral não leva desaforo pra casa, mesmo que para isso tenha de comprar uma briga.
No decorrer das oficinas, quando as conversas eram pautadas nas regras e nos códigos culturais que regem as relações grupais dentro da comunidade, as garotas comentavam que algumas meninas - inclusive algumas delas assim se colocavam - frequentemente recorriam a ameaça e briga, em que davam tapas e provocavam pequenas lesões, como forma de aceitação, respeito entre pares e permanência em grupos.

O uso de drogas, tanto lícitas quanto ilícitas, também foi relatado como elemento que compõe a vivência de uma menina de moral. As drogas, que são usadas entre os pares, são carregadas de significados que dizem respeito não só ao prazer envolvido em seu consumo mas sobretudo ao respeito conquistado e mantido devido à bravura de uma menina de moral, que ultrapassa as fronteiras do jogo permitido-proibido que permeia o uso de drogas no contexto social.

\section{Emprego de força física e ameaças verbais: outra perspectiva}

Muitos dos estudos sobre violência, de certa forma, abordam a temática em torno dos temores sociais provocados por violência criminalizante e, em geral, partem da perspectiva dessa violência. Segundo Guimarães e Campos (2007), a violência, em suas diversas facetas, ocupa lugar de destaque na vida cotidiana dos brasileiros, especialmente na parcela de população mais jovem, e a violência entre adolescentes e jovens é um fato que vem suscitando vários estudos.

Pesquisas realizadas por Adorno, Bordini e Lima (1999), no Núcleo de Estudos da Violência da Universidade de São Paulo (NEV/USP), revelam que tem havido tanto crescimento da participação de adolescentes em crimes violentos - comparativamente à participação da população em geral - como também aumento da vitimização desses jovens. 
No entanto, não há um único tipo de jovem, bem como não se pode pontuar um único tipo de jovem da periferia. Pode-se, entretanto, apontar algo que permeia suas realidades: a agravada exclusão social, que poderia provocar circunstanciais formas de violência na vida desses jovens em sua busca por reconhecimento e valorização de seus modos de vidas e de seus universos simbólicos (Castro, Abramovay, Rua, \& Andrade, 2001).

A partir da reflexão sobre o termo menina de moral, ante os relatos das garotas, ampliamos nosso entendimento acerca das formas e dos sentidos atribuídos ao emprego da força física e de ameaças verbais como formas de aceitação, respeito e permanência entre pares. Percebemos que essas práticas fazem parte do cotidiano das adolescentes e devem ser compreendidas dentro de um sistema sociocultural singular, propiciador igualmente de constituição e de sentidos de subjetividade particulares, como se pode visualizar nas seguintes falas, retiradas de um vídeo gravado em uma das oficinas:

- Renata: Eu fui tirar uma menina dentro da igreja.

- Socioeducadora 1: Ah?

- Renata: Eu fui tirar uma menina de dentro da igreja, mas ela não tava lá.

- Socioeducadora 1: Ela tava com teu namorado, foi?

- Renata: Ela veio tirar uma onda feia. Não foi nem porque tava com ele. Porque quando ela passava com a amiga, ela passava tirando onda, quando tava sozinha, ficava cabreira. Eu não tenho medo, eu com ninguém, sozinha, eu luto mesmo. Aí tomei banho, disse pra minha mãe que ia na escola, peguei o estilete e saí.

- Socioeducador: Pegaste o estilete, Renata? - Renata: Fui eu e meu primo lá. Meu primo me levou de bicicleta.

- Socioeducadora 1: Mas te levou já sabendo que tu ia...

- Renata: Sabendo, que eu disse a ele (batendo no peito).

- Socioeducadora 3: Aí o que tu ia fazer se ela tivesse lá, quando encontrasse com ela? - Renata: Tirar ela da igreja orando. Quando ela orasse, ia pegar ela por aqui: - Vamos lá fora, que a gente vai conversar! Quando os irmãos viessem (dizer) que isso é um espírito, eu ia dizer: - Bota lá, irmão, que não é nada, não. la cortar ela todinha de estilete e vinha embora.

Nesse trecho se observa que o motivo detonador do conflito não foi a possível traição, mas sim, tirar onda com a minha cara, que, por si, já seria um fato que uma menina de moral não deixaria passar em branco. Além disso, essa menina não necessita do auxílio de outrem para manter sua moral: "Eu não tenho medo, eu com ninguém, sozinha, eu luto mesmo".

Em outro diálogo, também se percebe que o emprego da força física é acionado, sobretudo como forma de manter o respeito entre os pares:

- Renata: O quê? Eu furei hominho aqui, na $4^{a}$ série, não foi não, Bianca? Deixei a ponta do lápis dentro dele.

- Socioeducadora 1: Hominho é um menino, é?

- Renata: Um homem.

- Bianca: Um homem? Tem certeza, Renata

? (risos)

- Socioeducadora 1: Hum!

- Renata: Ele era um tal de frango, mas eu digo que era homem. Ele botou o pé, eu caí, eu de saia, a galera tudinho zoando. Eu vou ficar por baixo, é? Quando ele se sentou, eu dei um chute na canela dele. Ele não gostou.

- Socioeducador 1: Eita pau, Renata!

- Renata: As meninas trancaram a porta da sala, mas foi luta nega. As meninas gritando: - Renata toma um lápis!, eu já fui furando ele, não quis nem saber onde pegasse.

- Socioeducador: Mas ele é grande também, Renata?

- Renata: Ele é maior do que eu, né, Bianca? (Bianca balança afirmativamente a cabeça).

- Renata: Maior do que eu pouca coisa.

- Socioeducador: Caramba! Mas depois tu não fica arrependida, não?

- Renata: Oxe! Já tô falando com ele e tudo. - Socioeducador: Ah! (risos de todos).

Não se pode deixar de mencionar os estigmas das adolescentes quando se referem ao garoto como frango ou quando alguém põe em dúvida se o garoto é mesmo um homem, em uma alusão a uma orientação não heterossexual. A seguir, são relatados a cena 
e os motivos do conflito: "Ele botou o pé, eu caí, eu de saia, a galera tudinho zoando. Eu vou ficar por baixo, é? Quando ele se sentou, eu dei um chute na canela dele. Ele não gostou". Uma menina de moral não fica por baixo diante de seus pares, ela reage e mostra que com ela não se brinca.

Apesar disso, esses episódios não são, em si, fatores que promovem discórdias permanentes entre os(as) envolvidos(as), nem mesmo são mencionados como forma ou ato de violência praticado contra o outro, ainda que se mencione o uso de estilete ou lápis como objeto perfurante. Além disso, em nenhum momento o sentimento de culpa ou de arrependimento foi evocado; ao contrário, os relatos foram permeados de sentimentos que fazem referência ao orgulho de resolver a situação. Assim, o emprego de força física e de ameaça verbal relatado pelas garotas na explicitação do termo menina de moral é predominantemente entendido como recurso que possibilita a construção e a manutenção de relações entre pares.

A violência entre adolescentes e jovens é amplamente divulgada na mídia e é motivo de preocupação de educadores(as), pais e estudiosos(as). Muitos(as) pesquisadores(as) têm se debruçado sobre o fenômeno, especialmente sobre a violência que ocorre em ambientes escolares. ${ }^{2}$ Em vários trabalhos, o conceito de bullying é utilizado para designar diferentes práticas de intimidação, exclusão, discriminação e agressões múltiplas entre os pares, entretanto, há pouca menção nesses estudos aos diferentes significados da violência para os jovens e adolescentes, em contextos distintos.

Uma exceção a isso é o trabalho de Simmons (2004), que, ao estudar bullying entre garotas brancas de classe média, nos Estados Unidos, enfatiza as diferentes expressões da violência a partir do recorte de classe, gênero, raça e etnia. Diferentemente das garotas de classe média, que usam agressividade dissimulada, as adolescentes de famílias predominantemente afro-americanas ou das classes trabalhadoras enfrentam os conflitos. A agressão não é evitada ou ignorada, ela é instrumento que confere ou mantém status e respeito. Além disso, as brigas têm o papel de criar ou fortalecer alianças e vínculos entre as meninas. Para a autora, em um contexto de dificuldades econômicas e ausência de cidadania, as garotas aprendem muito cedo que é preciso adquirir respeito e se defender quando são agredidas. Em muitas famílias, elas são incentivadas a não ter atitude passiva e a revidar quando provocadas.

O estudo de Simmons aponta alguns elementos importantes para a compreensão da violência entre os pares em contextos sociais localizados. No caso da comunidade das adolescentes desta pesquisa, o uso da força física e das agressões verbais que se expressa nos atos da menina de moral pode ser compreendido como elemento de autoafirmação. Por meio de brigas e intimidações, as meninas impõem respeito aos demais (sejam eles meninas ou meninos) e asseguram seu status no grupo. Além disso, a menina de moral flexibiliza a ideia de atributos masculinos e femininos rigidamente separados, e mobiliza recursos comumente associados ao domínio masculino: agressões físicas e confronto verbal direto com os pares.

\section{Uso de drogas entre as adolescentes}

Segundo a Secretaria Nacional Antidrogas (Ministério da Saúde, 2005), droga é qualquer substância que, não sendo produzida pelo organismo, tem a propriedade de atuar sobre um ou mais de seus sistemas, causando alterações em seu funcionamento. No Brasil e em outros países em desenvolvimento, o uso dessas substâncias tem assumido tendências preocupantes: feminização, ou seja, crescimento do uso e da dependência de drogas lícitas e ilícitas entre mulheres, juvenilização e pauperização.

Toma-se como exemplo desse duplo fenômeno o tabagismo: “Quase 100.000 
jovens começam a fumar a cada dia no mundo inteiro - destes, mais de 80.000 são jovens de países em desenvolvimento. A idade média de iniciação ao tabagismo é de 15 anos, o que fez com que a OMS passasse a considerar o tabagismo uma doença pediátrica" (Ministério da Saúde, 2004, p. 7). O uso de drogas - como relatado por algumas adolescentes participantes desta pesquisa - configura elemento mediador das relações sociais, e é fundamental na conquista do respeito dentro do microcosmo dessas adolescentes (Hygino \& Garcia, 2003).

Desafios, transgressões, questionamentos de crenças e valores, conflitos de gerações e experiências entre pares organizam as vivências socioafetivas e se integram na construção das subjetividades dos(as) adolescentes. Conforme aponta Calligaris (2000), como forma de resposta à moratória, o(a) adolescente cria, inventa e integra microssociedades, como grupos de amigos(as), grupos de estilo e até gangues. O uso de drogas também pode ser tomado como uma das chaves de acesso por meio das quais os(as) adolescentes dizem aos adultos que também já são adultos(as).

Os espaços em que algumas das participantes do projeto relataram fazer uso de várias substâncias psicoativas são diversos: escola e casa (nos banheiros, escondidas da família e dos professores), na rua, nos pagodes, nas festas. As drogas eleitas pelas garotas para consumo são: bebidas alcoólicas destiladas (cana) ou fermentadas (cerveja) e o loló - produto inalante composto por éter, clorofórmio e acetato de etila (Ministério da Saúde, 2005). Essas drogas permeiam o espaço da afetividade entre essas adolescentes, pois, já que são usadas em grupo, assumem centralidade nas conversas com os(as) amigos(as).

Em seus discursos, também se observam alguns marcadores de gênero quanto ao uso das drogas, que são justificados pelos efeitos visíveis pós-consumo (efeitos agudos). As meninas relataram não fazer uso da maconha devido à repercussão social dos efeitos agudos dessa droga (olhos vermelhos, por exemplo), o que, segundo elas, para os meninos, não ocorre de forma tão marcante.

As meninas de moral enfatizam a repercussão social do uso coletivo de drogas no grupo e o deleite envolvido nisso. As narrativas das situações em que elas usam substâncias psicoativas afirmam isso:

- Renata: O que a gente curte é tirar onda com a galera, cheirar um lolozinho. A gente fica muito doida, tonta, mas a tiração de onda com a turma é que é massa.

- Bianca: É muito bom fumar um cigarrinho, cheirar um loló na escola com as meninas. A gente tudinho escondida no banheiro na maior gréia, com medo que as professoras ou o diretor pegue. A gente tudo escondidinha, umas vigiam a porta e outras ficam cheirando loló.

As garotas também interpretaram o uso de drogas como comportamento que as distinguiria das meninas fracas, presas dentro de casa, portanto, fundamental à conquista do status de menina de moral.

- Renata: Oxe! Eu vou pros pagodes aqui do bairro. Chega de noite, eu saio. Eu me garanto! Quando o boyzinho tá a fim nas festas, ele vem logo com uma cerveja. Eu boto pra dentro, ele pode descer as grades todinhas, eu me garanto, bebo tudo. Pra mim não tem bebida forte.

Durante algumas oficinas nas quais foi abordada essa temática, os efeitos posteriores ao uso de drogas (ressaca, alterações no metabolismo e até doenças adquiridas pelo uso abusivo) eram tratados como secundários. Como uma das garotas nomeou, o que importa é a tiração de onda em grupo, o prazer envolvido em uma atividade de risco realizada com pessoas que compartilham afeto e respeito. 
Em certos casos, os prejuízos que algumas drogas causam à saúde eram até mesmo desconhecidos. Durante a vivência de uma dinâmica sobre as consequências do uso de drogas à saúde e os relatos das situações de risco decorrentes do uso dessas substâncias, algumas das adolescentes falaram: "Não pensava que um cigarrinho fazia isso tudo de mal. A gente usa e acha que não tem mal nenhum"; "Quando tava na fissura do loló, mas não tinha dinheiro, eu vendia cinco vidrinhos para ganhar um para mim. Conseguia eles com um cara que mexe com essas coisas de vender droga".

O uso dessas drogas não causa impacto negativo apenas nos(nas) adolescentes que vivem em classes consideradas subalternas, porém, devido a incontáveis fatores que permeiam suas vidas, faz-se necessário um olhar particularizado para esse público. De acordo com Martins, Manzato e Cruz (2005), devido às várias mudanças que ocorrem na transição entre a adolescência e a vida adulta, o uso de drogas pode ser facilitado ou evitado. Dessa forma, pode-se pensar sobre os fatores que previnem (evitam) e acentuam (facilitam) o uso de drogas. Todavia, "esses fatores não podem ser considerados em termos dicotômicos: de um lado, os protetivos, e, de outro, os de risco, como se fosse em termos de tudo ou nada, isto é, existindo os protetivos, automaticamente o adolescente ficaria protegido do envolvimento com drogas" (Martins et al., 2005, p. 313).

A experiência com as adolescentes durante o desenvolvimento do projeto mostrou que dois aspectos não devem ser negligenciados quando se discute o uso de drogas por uma menina de moral: o status, ou seja, o prestígio entre os pares, decorrente do consumo de drogas, e o prazer envolvido nessa experiência.
Os discursos das meninas participantes evidenciam que o uso dessas substâncias tem certa importância no jogo da conquista dos rapazes que são foco do seu desejo (nenhuma adolescente relatou que tinha também desejo por garotas ou que era homossexual). Uma delas relatou: "Quando tem um boyzinho a fim, ele vem logo com a cerveja ou loló para se chegar na gente... é bom ficar com um boyzinho, estando bêbada ou viajando no loló".

Das dez garotas, apenas uma não usava drogas, e novamente ela se nomeia a adolescente que gosta de estudar. Ela nem namora nem fica. Segundo as outras adolescentes, ela não fecha. Quando questionadas se pretendiam usar drogas para o resto da vida ou se desejavam parar e quando, caso desejassem, a maior parte do grupo se posicionou da seguinte forma: "A gente só vai usar enquanto é jovem, depois que a gente se casa e tem filhos, não é mais certo usar".

Algumas considerações As garotas, sempre que podiam, por meio de narrativas, afirmavam seu status no microcosmo da comunidade em que residem ou admiravam as façanhas de outras meninas de moral. Esse termo foi apresentado por elas, e só assume notória singularidade quando é considerado o lugar onde moram: a distância do centro, um território híbrido (meio rural e meio urbano), os altos índices de desemprego e subemprego, o poder do tráfico de drogas, o quase completo abandono por parte do Estado, a violência contra a mulher, a falta de espaços e alternativas de lazer. Como relatou uma das participantes,

- Aqui poucos policiais entram. Eles (os policiais) sabem que, se brincar, os meninos (traficantes e assaltantes da comunidade) matam! Olha, aqui só entram três policiais, 
mas quando entram, eles já vão atirando para tudo que é canto e com eles não tem conversa, é logo porrada. Eles batem até em mulher no meio da rua, eles se garantem na ignorância. Bola (referência à comunidade) era ruim, agora tá muito é péssimo!

Diante de um contexto em que a violência é elemento organizador do cotidiano, as construções da feminilidade e da juventude não poderiam ficar alheias às práticas de violência. Contudo, o emprego de força física e ameaça verbal, utilizado pela menina de moral em suas relações, revela outros elementos (conquista de respeito, manutenção de prestígio) que ultrapassam a simples classificação desses atos como comportamentos violentos, e sinalizam uma série de estratégias construídas ante as singularidades do contexto social no qual as adolescentes estão inseridas.

Assim como o emprego de força física e a ameaça verbal, o uso de drogas também não constitui fim em si mesmo. Permeado por teias de significados que ultrapassam o consumo como fato em si, o relato das adolescentes deixou explícito que o uso de drogas por uma menina de moral envolve não somente o prazer do consumo, pois é atravessado por uma gama de elementos que dizem respeito à conquista de status e à manutenção de respeito entre pares.

Pode-se pensar, a partir dessa experiência, que ações socioeducativas ou políticas públicas que visam ao empoderamento dos(as) adolescentes deveriam considerar as necessidades sociais específicas desse grupo e estruturar-se de forma que as(os) adolescentes sejam sujeitos das atividades. É importante contemplar as demandas e os interesses desse segmento, além de potencializar sua participação nos espaços e fóruns de controle social, pois, como revelam os discursos sobre meninas de moral, várias são as estratégias construídas pelos próprios adolescentes em meio à pluralidade de situações que tecem suas redes sociais.

Tal contribuição se torna necessária, principalmente, ao se tomar consciência de que muitos dos programas e projetos governamentais voltados para o público juvenil brasileiro não foram bem-sucedidos, devido à insuficiente compreensão das diversas realidades da juventude brasileira e das escassas oportunidades de participação dos jovens no processo de elaboração e de implementação de políticas públicas direcionadas para essa parcela da população (Castro \& Correia, 2005). As ações socioeducativas que objetivam o empoderamento no universo dos direitos sociais e sexuais de adolescentes do sexo feminino são fundamentais, porém, para reverter esse quadro de vulnerabilidade e exclusão social, e essas ações devem ser respaldadas e acompanhadas por políticas sociais que visem à transformação dessa realidade e à afirmação dos direitos de cidadania.

Por fim, acreditamos que a divulgação desta experiência possa ampliar os repertórios conceituais e teóricos sobre o universo juvenil, especialmente sobre adolescentes cujas experiências são demarcadas por vários eixos de diferenciação social, como classe, gênero, raça e geração. Esperamos, também, que estas reflexões possam contribuir, em alguma medida, para o embasamento de ações de psicólogos, assistentes sociais, educadores, estudantes e demais agentes sociais que trabalham com adolescentes de comunidades populares. 


\section{Rosineide de Lourdes Meira Cordeiro*}

Doutora em Psicologia Social pela Pontifícia Universidade Católica de São Paulo, São Paulo, SP - Brasil. Professora do Departamento de Serviço Social e do Programa de Pós-graduação em Psicologia, Universidade Federal de Pernambuco, Recife, PE - Brasil.

\section{Evandro Alves Barbosa Filho}

Estudante do curso de graduação em Serviço Social da Universidade Federal de Pernambuco, Recife, PE - Brasil. E-mail: evealves85@yahoo.com.br

\section{Giselle Maria Nanes Correia dos Santos}

Graduada em Psicologia. Mestranda do Programa Pós- Graduação em Antropologia da Universidade Federal de Pernambuco, Recife, PE - Brasil.

E-mail gisellesantos_2@yahoo.com.br

\section{Luanne Alves Oliveira}

Estudante do curso de graduação em Serviço Social da Universidade Federal de Pernambuco, Recife, PE - Brasil. Email: luanne_alves@yahoo.com.br

\section{Raíssa Barbosa Araújo}

Estudante do curso de graduação em Psicologia da Universidade Federal de Pernambuco, Recife, PE - Brasil. Email: raissabarbosa_@hotmail.com

*Endereço para envio de correspondência:

Rua Estevão de Sá 390/302 - Recife, PE - Brasil - CEP: 50740-270

E-mail: rocordeiro@uol.com.br

Recebido 31/10/2008, 1a Reformulação 3/7/2009, Aprovado 3/8/2009.

\section{Referências}

Adorno, S., Bordini, E., \& Lima, R. (1999). O adolescente e as mudanças na criminalidade urbana. São Paulo em perspectiva, 13(4), 62-74.

Calligaris, C. (2000). A adolescência. São Paulo: Publifolha.

Camacho, L. M. Y. (2001). As sutilezas das faces da violência nas práticas escolares. Educação e Pesquisa, 27(1), 123-140.

Castro, L., \& Correa, J. (2005). Juventude contemporânea: perspectivas nacionais e internacionais. Rio de Janeiro: NAU.

Castro, M., Abromovay, M., Rua, M. G., \& Andrade, E. R. (2001). Cultivando vidas e desarmando violências: experiências em educação, cultura, lazer, esporte e cidadania com jovens em situação de pobreza. Brasília, DF: UNESCO.

De Leone, R. (1979). Small future: Children, inequality and the limits of liberal reform. New York: Harcout.

Freyre, G. (1960). Brasis, Brasil e Brasília: sugestões em torno de problemas brasileiros de unidade e diversidade e das relações de alguns deles com problemas gerais de pluralismo étnico e cultural. Lisboa: Livros do Brasil.

Guimarães, S., \& Campos, P. (2007). Norma social violenta: um estudo da representação social da violência em adolescentes. Psicologia: Reflexão e Crítica, 20(2), 188-196.
Hirata, H. (2002). Reorganização da produção e transformação do trabalho: uma nova divisão sexual? In C. Bruschini \& S. Unbenahaum (Orgs.), Gênero, democracia e sociedade. São Paulo: Fundação Carlos Chagas.

Hygino, A., \& Garcia, J. (2003). Drogas: a permanente (re) encarnação do mal. Serviço Social e Sociedade, 74, 31-41.

Martins, R. A., Manzato, A. J., \& Cruz, L. N. (2005). O uso de bebidas alcoólicas entre adolescentes. In L. R. Castro \& J. Correa (Orgs.), Juventude contemporânea: perspectivas nacionais e internacionais. Rio de Janeiro: NAU.

Ministério da Saúde. (2004). Ação global para o controle do tabaco: por um mundo sem tabaco - mobilização da sociedade civil (3a ed.). Rio de Janeiro: INCA.

Ministério da Saúde. (2005). Drogas: cartilha sobre maconha, cocaína e inalantes. Brasília, DF: Senad.

Simmons, R. (2004). Garotas fora do jogo: a cultura oculta da agressão entre as meninas. Rio de Janeiro: Rocco.

UNESCO. (2003). Violência na escola: América Latina e Caribe. Brasília, DF: Autor. 